\title{
Noise Properties for Filtered Back Projection in CT Reconstruction
}

\author{
Kwonsu, Chon \\ Department of Radiological Science, The Graduate School, Catholic University of Daegu \\ 필터보정역투영 $\mathrm{CT}$ 영상재구성방법에서 잡음 특성 \\ 천권수 \\ 대구가톨릭대학교 방사선학과
}

\begin{abstract}
The filtered back projection in the image reconstruction algorithms for the clinic computed tomography system has been widely used. Noise of the reconstructed image was examined under the input noise for parallel and fan beam geometries. The reconstruction images of $512 \times 512$ size were carried out under 360 and 720 projection by the Visual $\mathrm{C}++$ for parallel beam and fan beam, respectively, and those agreed with the original Shepp-Logan head phantom very much. Noise was generated because of intrinsic restriction (finite number of projections) for the image reconstruction algorithm, filtered back projection, when no input noise was applied. Because the result noise was rapidly increased under $0.5 \%$ input noise ratio, technologies for reducing noise in CT system and image processing is important.
\end{abstract}

Keyword : Computed Tomography, Image Reconstruction, Parallel Beam, Fan Beam, Noise

\section{요 약}

전산화단층촬영장치의 영상재구성방법으로 필터보정역투영법이 광범위하게 사용되고 있다. 평행빔과 부채살빔의 재구성에 사용되는 투영에 잡음이 포함되었을 때 재구성 된 영상의 잡음을 살펴보았다. 평행빔과 부채살 구조에서 각 각 360 개, 720 개의 투영으로 $512 \times 512$ 크기로 Visual C++을 이용하여 영상재구성하였고, 원본 Shepp-Logan 두부 모형을 매우 잘 복원한다는 것을 확인하였다. 필터보정역투영법의 현실적인 접근(유한한 투영 개수)으로 인해 입력 잡 음이 없어도 영상재구성 과정에서 잡음이 발생하였다. 입력 잡음비 $0.5 \%$ 이하에서 잡음이 빠르게 증가하기 때문에 $\mathrm{CT}$ 장치의 잡음 제거 기술 및 영상처리 기법의 개발이 필요할 것이다.

중심단어: 전산화단층촬영, 영상재구성, 평행빔, 부채살빔, 노이즈

\section{INTRODUCTION}

엑스선(X-ray)를 이용한 전산화단층촬영기법 (Computed Tomography, CT) ${ }^{[1]}$ 은 3 차원 대상(Object) 물 체의 내부 구조를 파악하는데 매우 편리한 방법으로,
산업 ${ }^{[2]}$ 및 의료 ${ }^{[3]}$ 분야 등에 광범위 하게 사용되고 있 다. 광원에서 발생된 엑스선이 대상 물체를 투과하면, 대상을 구성하고 있는 물질의 종류 및 구조에 따라 엑 스선의 감약(Attenuation)이 다르게 되어 검출기에 기록 된다. 대상 물체 또는 광원과 검출기를 회전시키면서 
투영(Projection)을 획득하여 영상재구성(Image Reconstruction)을 수행하면 2차원 단면 영상을 얻을 수 있다 ${ }^{[4]}$.

감약 정보를 얻는 광원과 검출기의 형태에 따라 평 행빔(Parallel Beam), 부채살빔(Fan Beam), 원뿔빔(Cone Beam) 구조로 구분된다 ${ }^{[5]}$. CT에서 물질의 감약 정보는 통상 디지털 검출기로 추출된다. 디지털 검출기는 엑 스선의 검출을 담당하는 검출 픽셀이 규칙적으로 배 열되어 있고, 비슷한 감도를 가지고 있다. 그러나 실제 제작된 검출기의 각 픽셀은 평균적으로 비슷한 감도 를 가지지만 모든 픽셀들이 같은 감도를 가지지 않는 다 ${ }^{[6]}$.

본 연구는 평행빔 및 부채살빔 구조의 $\mathrm{CT}$ 에서 각 투영의 감약 정보에 잡음(Noise)이 추가되었을 때 재구 성된 영상에 어떤 영향이 있는지를 다룬다. 수학적인 Shepp-Logan 두부 모형(Head Phantom $)^{[7]}$ 을 구성하고, 필터보정역투영(Filtered Back Projection) 영상재구성 방 법으로 2 차원 단면 영상을 얻는다 ${ }^{[8]}$. 재구성된 영상의 정확성을 평가한 후, 투영의 잡음 추가에 따른 영향을 살펴본다.

\section{THEORY AND MATHEMATICAL MODEL}

\section{1. 영상재구성의 원리}

영상재구성을 통해 얻고자 하는 대상의 단면을 기 술하는 함수를 $\mathrm{f}(\mathrm{x}, \mathrm{y})$ 라고 하면 푸리에 역변환(Fourier Inverse Transformation)은

$$
f(x, y)=\iint F(u, v) e^{i 2 \pi(u x+v y)} d u d v
$$

가 된다. 푸리에 공간의 $\mathrm{F}(\mathrm{u}, \mathrm{v})$ 함수를 구해서 푸리에 역변환을 수행하면 임의의 함수 $\mathrm{f}(\mathrm{x}, \mathrm{y})$ 를 얻을 수 있 다. $\mathrm{F}(\mathrm{u}, \mathrm{v})$ 는 임의의 각도에서 얻은 1 차원 투영의 푸리 에 변환이 2 차원 $(\mathrm{u}, \mathrm{v})$ 공간에서 직선의 정보와 일치 하게 된다는 푸리에 조각 정리(Fourier Slice Theorem)를 이용하여 구할 수 있다 ${ }^{[8]}$. 투영을 얻는 CT의 구조에 따라 $0^{\circ}-180^{\circ}$ 또는 $0^{\circ}-360^{\circ}$ 사이에서 투영을 푸리에 변환하여 2차원 $(\mathrm{u}, \mathrm{v})$ 주파수 공간을 채우면 2차원의 $\mathrm{F}(\mathrm{u}, \mathrm{v})$ 를 얻을 수 있다. 통상적으로는 시노그램 (Sinogram)을 한 번에 푸리에 변환하여 2차원 $\mathrm{F}(\mathrm{u}, \mathrm{v})$ 를
얻는다. 이론적으로 무한대의 투영을 얻는다면 온전한 $\mathrm{F}(\mathrm{u}, \mathrm{v})$ 를 얻을 수 있지만 현실적으로는 불가능하다. 따라서 유한한 투영을 이용한 CT의 단면영상은 근사 적일 수밖에 없다.

\section{Shepp-Logan 두부 모형}

영상재구성의 정확성을 평가하기 위해서 SheppLogan 두부 모형이 많이 이용된다. 이 수학적 모형은 두부의 단면을 묘사하는 것으로 10 개의 타원으로 구성 되어 있다. Fig. 1은 $512 \times 512$ 매트릭스(Matrix) 크기로 영상화한 두부 모형의 영상을 나타낸 것이다. 이 논문 의 모든 영상은 Visual C++ (Microsoft Visual Studio 2010) MFC 기반에서 구현되었다.

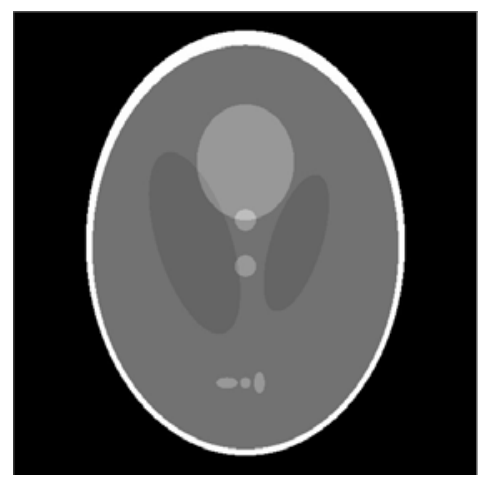

Fig. 1. Shepp-Logan head phantom of $512 \times 512$ matrix sizes.

\section{RECONSTRUCTION}

\section{1. 평행빔에 대한 영상재구성}

평행빔을 이용하여 얻은 감약 정보(투영)를 이용하 여 영상을 재구성하기 위해서는 평행빔 재구성 방법 을 사용해야 한다. 초창기 CT에서 감약 정보를 얻은 형태와 매우 비슷하다. 광원과 검출기 관련 기술이 발 전하여 오늘날에는 평행빔 구조로 투영을 얻는 경우 가 거의 없으나 영상재구성의 성능평가를 위해 많이 사용된다.

평행빔 구조에서 영상재구성을 살펴보기 위해 직각 좌표계로 표현된 푸리에 역변환인 Eq. (1)을 극좌표(w, $\ominus)$ 로 변환하여 각도 $(\Theta)$ 에 대한 적분을 $0^{\circ}$ 에서 $180^{\circ}$, 그 리고 $180^{\circ}$ 에서 $360^{\circ}$ 로 나누어 정리하여 하나의 식으로 
종합하면

$$
f(x, y)=\int_{0}^{\pi}\left[\int_{0}^{\infty} S_{\theta}(w)|w| e^{i 2 \pi w t} d w\right] d \theta
$$

를 얻는다. 여기서 $S_{\theta}(w)$ 는 시노그램을 푸리에 변환 한 것이다. Eq. (2) 적분은

$$
f(x, y)=\int_{0}^{\pi} Q_{\theta}(x \cos \theta+y \sin \theta) d \theta
$$

로 표현할 수 있고,

$$
Q_{\theta}(t)=\int_{0}^{\infty} S_{\theta}(w)|w| e^{i 2 \pi w t} d w
$$

가 된다. 위의 Eq. (4) 적분은 $|\mathrm{w}|$ 에 의해 필터링 (Filtering) 되는 것으로 해석될 수 있다.

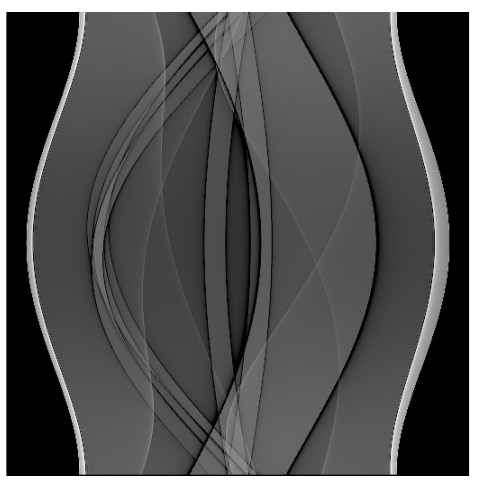

(a) Filtered sinogram

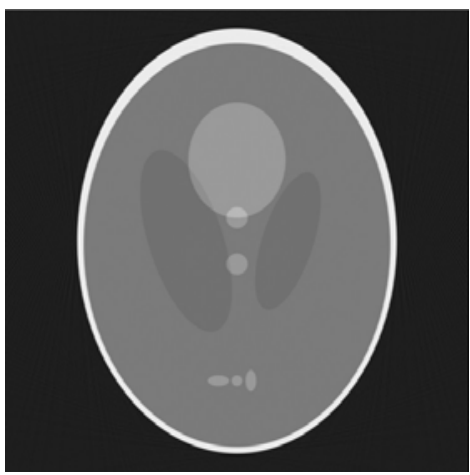

(b) Reconstructed image

Fig. 2. The filtered sinogram (a) and the reconstructed image for the Shepp-Logan head phantom with 360 views under the

parallel beam geometry. By the filtering the edge of the sinogram was cleared.
필터를 무시하고 영상재구성을 수행하면 경계가 매 우 흐린 영상이 얻어진다. 따라서 이 적분을 “필터보 정투영”(filtered projection)이라고 한다. 이 적분을 각도 별로 모으면 필터가 적용된 시노그램이 얻어진다. Fig. 2 (a)는 $0.5^{\circ}$ 간격으로 360 개의 투영 데이터를 주파수 공 간에서 $|\mathrm{w}|$ 로 필터(Lam-Rak Filter) ${ }^{[9]}$ 처리한 시노그램 을 나타낸 것이다. 필터 처리로 인해 경계가 명확해진 것을 확인할 수 있다. Eq. (3)은 각각의 $\Theta$ 에 대한 필터 처리된 투영을 적분함으로써 $\mathrm{f}(\mathrm{x}, \mathrm{y})$ 를 얻을 수 있는 것 을 나타낸다. Fig. 2 (b)는 필터 처리된 시노그램으로 얻은 Shepp-Logan 두부 모형의 영상을 나타낸 것이다. 원본 영상을 매우 잘 복원한 것을 알 수 있다.

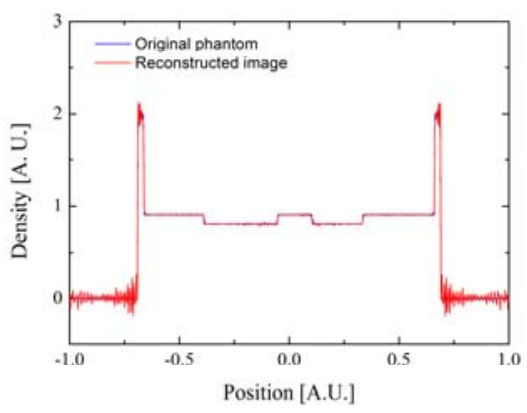

(a) $y=0.0$

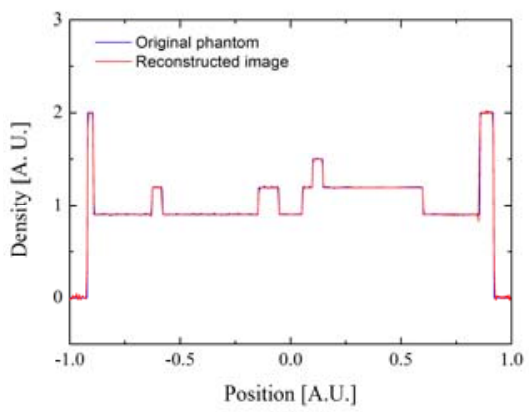

(b) $x=0.0$

Fig. 3. Comparison of line profiles for the original image and the reconstruction image of Shepp-Logan head phantom with 360 views.

영상재구성의 정확성을 확인하기 위하여 원본 Shepp-Logan 영상과 재구성 된 영상의 일차원 밀도 값 을 비교하였다. 모든 영역에서 두 영상의 밀도값이 매 우 비슷하다는 것을 확인하였다. Fig. 3 은 $\mathrm{y}=0.0$ 과 $\mathrm{x}$ 
$=0.0$ 의 위치에 대해 두 영상의 밀도 값을 비교한 것 이다. 물질의 경계 부분도 상당히 잘 일치한다는 것을 확인할 수 있고, 밀도차가 큰 경계 부분에서 상당한 잡음이 발생한다는 것을 알 수 있다. 배경 부분과 밀 도가 높은 부분을 제외하고는 잡음의 진폭은 매우 적 다. 상대적 밀도차가 큰 부분에서 잡음이 크게 증가한 다는 것을 알 수 있다. 금속과 같이 밀도가 높은 물질 에 대해 영상재구성 할 때는 경계 부근에서 잡음이 증 가할 것이라는 것을 알 수 있다.

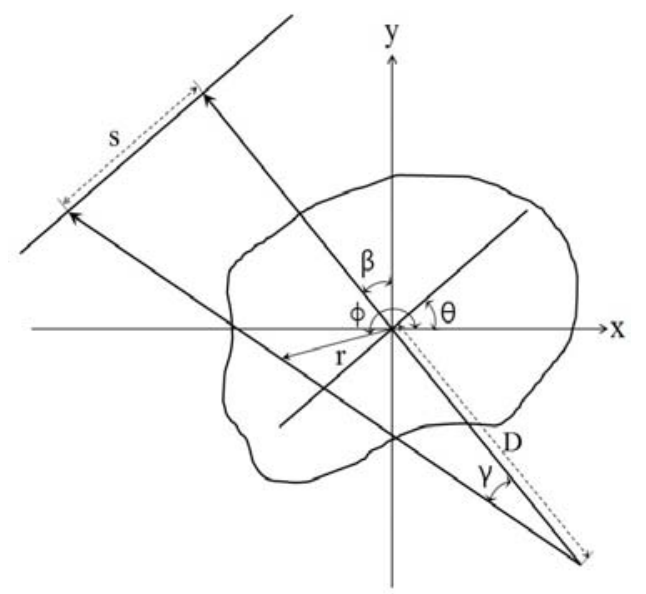

Fig. 4. Fan beam geometry.

\section{2. 부채살빔에 대한 영상재구성}

부채살빔에 대해 검출기 픽셀이 균일한 간격으로 배열되어 있는 경우를 고려하자. Eq. (3)은 극좌표 $(r, \phi)$ 인

$$
f(r, \phi)=\frac{1}{2} \int_{0}^{2 \pi} \frac{1}{U^{2}} Q_{\beta}\left(s^{\prime}\right) d \beta
$$

로 표현될 수 있다. 여기서

$$
\begin{aligned}
& Q_{\beta}(s)=\frac{D}{\sqrt{D^{2}+s^{2}}} R_{\beta}(s) * h(s) \\
& U=\frac{D+r \sin (\beta-\phi)}{D}
\end{aligned}
$$

이다. Eq. (6)의 * 표시는 1차원 컨볼루션(Convolution) 을 의미하고, $\mathrm{R}(\mathrm{s})$ 과 $\mathrm{h}(\mathrm{s})$ 는 각각 부채살빔에 의해 얻어 지는 투영과 필터를 나타낸다. $\mathrm{D}$ 와 s는 Fig. 4와 같이 각각 광원과 회전 중심까지의 거리와 검출기의 중심
에서 물체를 투과한 임의의 엑스선이 검출기에 도달 한 점(또는 픽셀) 사이의 거리이다. Eq. (5)에서 $1 / 2$ 는 각도가 $0^{\circ}-360^{\circ}$ 로 확대되면서 나타나는 인자이고 $1 / \mathrm{U}^{2}$ 은 부채살빔이 물체를 투과할 때 광원에 가까이 있는 부분과 먼 부분의 광선의 밀도를 보정해주는 인 자이다. 즉, 에너지 보존 법칙이 성립하도록 하는 인자 이다. 부채살빔에 의한 투영의 영상재구성은 평행빔의 경우와 매우 유사하다. 즉, 평행빔의 경우에 보정 인자 가 추가된 형태를 갖는다. 같은 각도를 가지도록 검출 기가 배치된 구조도 비슷하게 수식이 유도될 수 있다. 부채살빔에 의한 투영을 이용하여 Shepp-Logan 두부 모형을 재구성한 영상을 Fig. 5 (a)에 표시하였고, $\mathrm{y}=$ 0.0 위치에서의 밀도를 팬텀 영상과 재구성된 영상을 서로 비교하였다. 평행빔의 경우와 마찬가지로 비슷한 잡음 양상을 보였다.

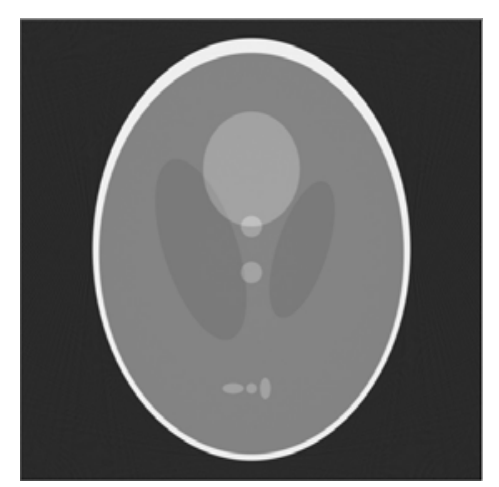

(a) Reconstructed image

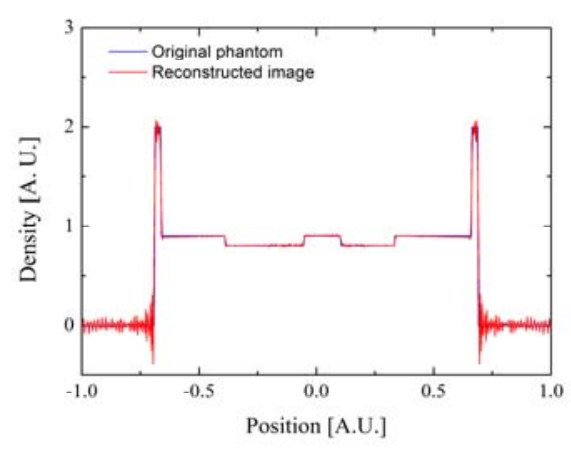

(b) Profile comparison at $y=0.0$

Fig. 5. Reconstruction Image (a) and profile comparison at y $=0.0$ (b) for fan beam geometry. In the reconstruction, 720 views $D=5$ [A.U.] were used. 


\section{NOISE EFFECTS}

\section{1. 잡음 발생 및 관심영역}

검출기가 모두 같은 감도로 광자를 검출하지 않기 때문에 잡음 발생은 필수적일수 밖에 없다. 이론적으 로 얻어지는 투영에 표준편차 $\sigma$ 인 가우시안 백색 잡 음(Gaussian White Noise)을 추가하였고, 잡음은 Shepp-Logan 두부 팬텀의 최고 밀도값(2.0)의 상대비인 잡음비(Noise Ratio, NR)

$$
N R=\frac{\sigma}{2.0} \times 100 \%
$$

로 표시하였다. 잡음의 영상재구성에 의한 영향을 관 심영역에서 표준편차를 구하여 잡음비로 표시하였다. 가우시안 무작위(Random) 잡음은 Box-Muller 변환[10] 알고리즘으로 구현하였고, 발생된 잡음이 가우시안 분 포를 따른다는 것을 히스토그램을 통하여 확인하였다.

관심영역(Region of Interest, ROI)은 총 7곳을 선정하 였으며, $512 \times 512$ 매트릭스 크기에서 $52 \times 52$ 크기로 하였다. 이 관심영역은 전체 면적의 $1 \%$ 에 해당하는 크 기이다. 두부 밖은 배경에 해당하기 때문에 관심영역 으로 선택하지 않았다. Fig. 6은 잡음 효과의 평가에 사 용된 관심영역을 표시한 것이다. 잡음비가 $0.66 \%$ 일 때 평행빔과 부채살빔에 대해 재구성된 영상을 Fig. 7에 표시하였다.

\section{2. 영상재구성과 잡음}

평행빔 및 부채살빔 구조에서 7개 ROI 영역에서 잡 음비를 평가하였다. 잡음 제거를 위해 Lam-Rak 필터를 사용하였고, 평행빔과 부채살빔에서는 각각 360 개와 720 개의 투영 $\left(0.5^{\circ}\right.$ 당 1 개의 투영)을 사용하였다. Table 2 와 Table 3 은 평행빔과 부채살빔에 대한 잡음비를 나 타낸 것이다. 두 영상재구성에서 입력 잡음비가 증가 할수록 결과 잡음비도 증가하였다. 밀도가 서로 다른 경우에 영상재구성의 잡음에 대한 영향은 비슷하다는 것을 $\mathrm{ROI} \mathrm{A,} \mathrm{B,} \mathrm{C의} \mathrm{값으로} \mathrm{알} \mathrm{수} \mathrm{있다.} \mathrm{ROI} \mathrm{D와} \mathrm{F는}$ 중심에서 같은 위치에 있으나 주변의 밀도차가 서로 다른 경우를 나타내고, ROI E와 $\mathrm{G}$ 는 중심에서 서로 같은 위치에 있으나 밀도차가 비슷한 경우이다. 부채
살빔의 경우 $\mathrm{F}$ 가 $\mathrm{G}$ 보다 평균 $1.5 \%$ 높게 나타난다. 반 면 평행빔의 경우는 거의 같다.

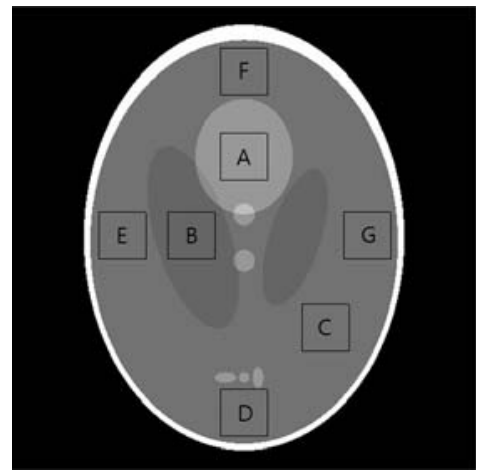

Fig. 6. Region of interest for noise evaluation in Shepp-Logan head phantom.

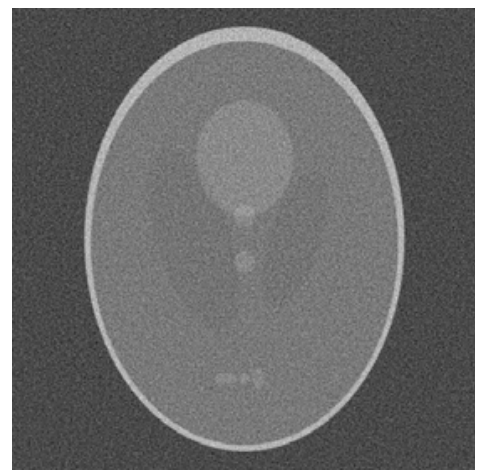

(a) Parallel beam

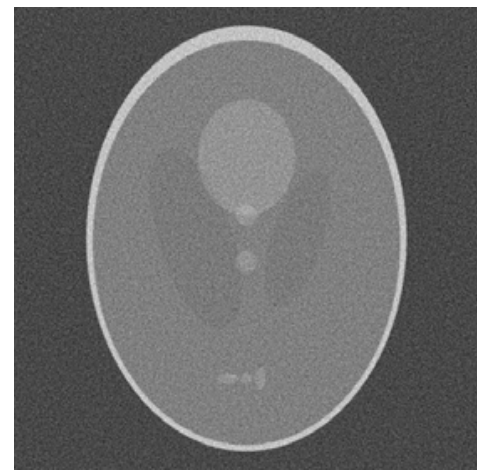

(b) Fan beam

Fig. 7. Reconstructed images under noise ratio of $0.66 \%$ for parallel (a) and fan (b) beam geometry.

Fig. 8은 두 재구성방법에서 ROI A, F, G에 대한 잡 음비를 나타낸 것이다. Fig. 8 (b)로부터 잡음비 증가 
양상에서 $1.5 \%$ 의 차이는 거의 무시가능하다는 것을 알 수 있다. 실선으로 된 그래프는 각각의 경우에 대 해 ROI A의 잡음비에 대한 최적 피팅(fitting)을 나타낸 것이다. 두 경우 모두 초기 잡음에 대해 빠르게 증가 하다가 서서히 포화되는 양상을 보인다. 두 재구성 방 법에서 잡음비는 $0.66 \%$ 의 입력 잡음에 대해 $1.17 \%$ 의 최대 차이를 보였다. 그러나 전반적으로 부채살빔 재 구성방법이 더 낮은 잡음비를 준다는 것을 알 수 있다. 입력 잡음이 작은 경우(대략 $0.5 \%$ 미만의 영역)에 재 구성된 영상의 잡음은 빠르게 증가하기 때문에 CT 장 치 및 영상처리에서 진폭이 작은 잡음을 줄이는 기술 개발이 영상의 품질을 높이는데 중요하다는 것을 알 수 있다.

\section{DISCUSSION}

입력 잡음에 대해 출력되는 영상의 잡음은 매우 민 감하게 반응하고 있다. 특히 추가적인 입력 잡음이 없 는 경우에도 영상재구성 알고리즘 자체에 의해 잡음 이 발생되었다.

Table 2. Noise ratio for parallel beam geometry.

\begin{tabular}{cccccccc}
\hline 잡음 & \multicolumn{7}{c}{$\mathrm{R}$ OI } \\
\cline { 2 - 7 } 비(\%) & $\mathrm{A}(\%)$ & $\mathrm{B}(\%)$ & $\mathrm{C}(\%)$ & $\mathrm{D}(\%)$ & $\mathrm{E}(\%)$ & $\mathrm{F}(\%)$ & $\mathrm{G}(\%)$ \\
\hline 0.0 & 0.10 & 0.15 & 0.12 & 0.17 & 0.10 & 0.21 & 0.10 \\
0.2 & 3.51 & 3.61 & 3.67 & 3.64 & 3.67 & 3.65 & 3.64 \\
0.4 & 5.45 & 5.67 & 5.48 & 5.43 & 5.52 & 5.52 & 5.70 \\
0.6 & 6.54 & 6.64 & 6.69 & 6.54 & 6.71 & 6.61 & 6.78 \\
0.8 & 7.90 & 7.52 & 7.52 & 7.69 & 7.61 & 7.55 & 7.68 \\
1.0 & 8.16 & 8.20 & 7.89 & 8.34 & 8.12 & 8.12 & 8.10 \\
1.2 & 8.87 & 8.81 & 9.01 & 8.87 & 8.86 & 8.68 & 8.81 \\
1.4 & 9.36 & 9.16 & 9.33 & 9.14 & 9.18 & 9.21 & 9.10 \\
1.6 & 9.32 & 9.39 & 9.00 & 9.16 & 9.45 & 9.47 & 9.29 \\
1.8 & 9.84 & 9.46 & 9.53 & 9.79 & 9.56 & 9.52 & 9.56 \\
\hline & & & & & & &
\end{tabular}

Table 3. Noise ratio for fan beam geometry.

\begin{tabular}{cccccccc}
\hline 잡음 & \multicolumn{7}{c}{$\mathrm{ROI}$} \\
\cline { 2 - 7 } 비(\%) & $\mathrm{A}(\%)$ & $\mathrm{B}(\%)$ & $\mathrm{C}(\%)$ & $\mathrm{D}(\%)$ & $\mathrm{E}(\%)$ & $\mathrm{F}(\%)$ & $\mathrm{G}(\%)$ \\
\hline 0.0 & 0.11 & 0.14 & 0.15 & 0.19 & 0.14 & 0.20 & 0.14 \\
0.2 & 2.68 & 2.67 & 2.65 & 2.75 & 2.76 & 2.85 & 2.63 \\
0.4 & 4.36 & 4.33 & 4.50 & 4.57 & 4.41 & 4.61 & 4.50 \\
0.6 & 5.91 & 5.64 & 5.87 & 5.90 & 5.76 & 6.05 & 5.89 \\
0.8 & 6.60 & 6.67 & 6.50 & 6.74 & 6.64 & 6.81 & 6.67 \\
1.0 & 7.28 & 7.13 & 7.25 & 7.34 & 7.24 & 7.39 & 7.41 \\
1.2 & 7.76 & 7.53 & 7.66 & 8.05 & 7.75 & 7.75 & 7.81 \\
1.4 & 8.37 & 8.24 & 8.26 & 8.51 & 8.44 & 8.56 & 8.31 \\
1.6 & 8.72 & 8.45 & 8.61 & 9.02 & 8.51 & 8.69 & 8.57 \\
1.8 & 8.99 & 8.87 & 8.83 & 9.20 & 9.01 & 9.13 & 9.06 \\
\hline
\end{tabular}

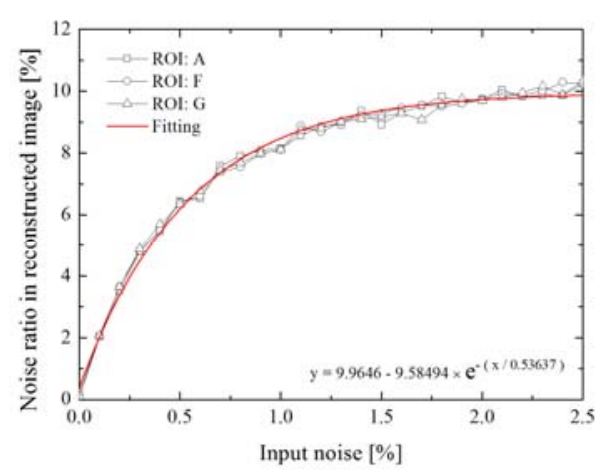

(a) Parallel beam

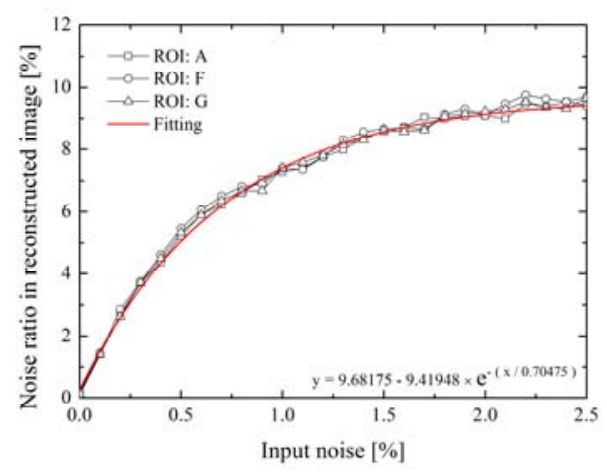

(b) Fan beam

Fig. 8. Noise ratio in $\mathrm{ROI} A, F$, and $\mathrm{G}$ for parallel and fan beam reconstruction. Fitting curves, solid lines, in (a) and (b) are for each $\mathrm{ROI} A$.

입력 잡음비가 $0.0 \%$ 라는 것은 CT장치가 가지고 있 는 기계적, 전기적인 잡음 요인이 없는 경우이다. 그러 나 입력 잡음비가 $0.0 \%$ 인 경우에도 각 ROI 값은 0 이 아닌 출력 잡음비를 보였다. 이는 필터보정역투영방법 이 완벽한 투영 데이터로부터 온전한 영상을 재구성 
하지 못하는 근사적 방법이라는 것을 간접적으로 보 이는 결과라 할 수 있다.

잡음 발생은 필터링 과정에 사용된 Ram-Lak 필터가 높은 주파수 성분을 잘 통과시키기 때문에 백색 잡음 을 효과적으로 제거하지 못하는 것이 하나의 원인이 다. 백색 잡음을 효과적으로 제거할 수 있는 필터(예, Hann Filter ${ }^{[11]}$ )가 있으나, 대상 물질의 경계를 구분할 수 있는 능력(공간분해능)이 떨어지는 단점이 발생한 다. 즉, 공간분해능을 위해서는 고주파 통과 특성이 우 수한 Ram-Lak 필터가 추천되나 신호대 잡음비, 대조도 를 향상시키기 위해서는 저주파 특성이 우수한 필터 의 사용이 요구된다. 따라서 사용 목적에 적합한 필터 를 선택할 수 있도록 다양한 필터를 제공하는 것이 바 람직하다.

투영의 개수도 영상재구성에 영향을 준다. 평행빔 의 경우 720 개의 투영을 사용하여(360개 투영의 2배) 입력 잡음이 없는 경우에 재구성된 영상의 잡음은 ROI 별로, $0.07 \%, 0.14 \%, 0.10 \%, 0.06 \%, 0.09 \%, 0.05 \%$, $0.08 \%$ 를 보였다. 이는 360 개의 투영에 비해서 낮은 잡 음 값이나, 큰 차이를 보이지는 않는다. 부채살빔의 경 우에도 비슷한 값을 보였다. 이것으로부터 투영의 개 수 즉, 영상재구성시 사용되는 투영 영상의 개수도 재 구성되는 영상의 품질에 영향을 준다는 것을 알 수 있 다. 그러나 2 배로 투영 개수를 증가시켜도 잡음비는 두 배만큼 향상되지 않는다. 1,440 개의 투영을 사용했 을 때는 평행빔의 경우, 잡음비는 720 의 투영의 경우 와 거의 같은 잡음비를 보였다. 투영의 개수가 많아지 면 영상재구성의 속도 측면에서 손실이 발생하기 때 문에 영상의 품질과 투영의 개수 또는 영상재구성 시 간 사이의 관계를 고려해야 한다.

원뿔빔 영상재구성 기법으로 많이 사용되고 있는 $\mathrm{FDK}$ 알고리즘1ㅣ은 부채살빔에 대한 알고리즘을 3 차 원으로 확대한 것으로 볼 수 있기 때문에 콘빔 재구성 된 단면 영상에서도 초기 잡음을 제거하는 것이 영상 의 품질 측면에서 중요할 것이다.

\section{CONCLUSION}

영상에서 잡음은 피할 수 없는 인자이다. 평행빔과 부채살빔 구조에서 필터보정역투영방법으로 영상을
재구성했을 때의 잡음 입력에 대한 출력을 살펴보았 다. 입력 잡음이 없는 경우에도 필터보정역투영방법에 의해 잡음이 발생되었다. 7 개의 ROI에 대해서는 잡음 비 차이는 거의 없었으나, 평행빔의 경우가 부채살빔 의 경우 보다 잡음에 더 민감하게 반응한다는 것을 확 인하였다. 입력 잡음이 작은 경우(대략 $0.5 \%$ 미만)에 재구성된 영상의 잡음은 빠르게 증가하기 때문에 장 치 및 영상 처리 측면에서 잡음을 줄이려는 기술개발 이 필요할 것이다.

\section{Acknowledgements}

이 논문은 2014년도 대구가톨릭대학교 교내연구비 지원에 의한 것임.

\section{Reference}

[1] G.N. Hounsfield, "Computerized transverse axial scanning (tomography): I. Description of system,” Br. J. Radiol. Vol. 46, pp1016-1022, 1973.

[2] B.S.B. Sun W, R.K. Leach, "An overview of industrial X-ray computed tomography,” NPL Report ENG 32, 2012.

[3] W.A. Kalender, "X-ray computed tomography," Phy. Med. Biol. Vol. 51, ppR29-R43, 2006.

[4] Ludwig D, "The Radon transform on Euclidean space," Comm. Pure and Appl. Math., Vol.19, pp49-81, 1966.

[5] J. Hsieh, Computed Tomography: Principles, Design, Artifacts, and Recent Advances, SPIE Press, Bellingham, Washington USA, 2003.

[6] L.W. Goldman, "Principles of CT and CT Technology," Journal of Nuclear Medicine Technology, Vol. 35 No. 3, pp115-128, 2007.

[7] L.A. Shepp, B.F. Logan, "The Fourier Reconstruction of a Head Section," IEEE Trans. Nucl. Sci., Vol. 21, pp21-43, 1974.

[8] A.C. Kak, M. Slaney, Principles of Computerized Tomographic Imaging, IEEE Press, New York, 1988.

[9] G.N. Ramachandran, A.V. Lakhshminarayanan, "Three-dimensional reconstruction from radiographs and electron micrographs: Application of convolution instead of Fourier transforms,' Proc.Natl.Sci. Acad. USA, Vol.68, pp2236-2240, 1971.

[10] G.E.P. Box, M.E. Mull, "A note on the generation of random normal deviates,” Annals Math. Stat, Vol. 29, pp610-611, 1958.

[11] B. Kang, "Quantitative Evaluation of CT Artifact Elimination 
with various Cut-off Frequency of Hann Filter," Journal of the Korea Society of Radiology, Vol. 2, No. 3, pp5-9, 2008.

[12] L.A. Feldkamp, L.C. Davis, J.W. Kress, "Practical cone-beam algorithm,” J. Opt. Soc. Am., Vol 1, No. 6, pp612-619, 1984 